\title{
Extraction of Metastable Icosahedral Quasicrystalline Nanoparticles from Zirconium and Hafnium Based Metallic Glasses
}

\author{
Michael Bauer ${ }^{1}$, Dingqiang $\mathrm{Li}^{2}$, Matt Caputo ${ }^{1}$, Limin Wang ${ }^{3}$, Chunfei $\mathrm{Li}^{1}$ \\ ${ }^{1}$ Department of Physics, Clarion University, Clarion, PA 16214, United States \\ ${ }^{2}$ Department of Chemistry, Youngstown State University, Youngstown, OH 44555, United States \\ ${ }^{3}$ Key Laboratory of Rare Earth Chemistry and Physics, Changchun Institute of Applied Chemistry, \\ Chinese Academy of Science, Changchun,130022, China
}

Metastable icosahedral quasicrystalline nanoparticles (MIQNP) precipitate in the initial crystallization processes of some selected Zirconium and Hafnium based metallic glasses. All such particles reported so far are embedded in a residual glassy matrix. It is predicted that if these are separated as free standing particles they can be applied to a variety of fields. Metallic glasses of compositions $\mathrm{Zr}_{70} \mathrm{Cu}_{27.5} \mathrm{Rh}_{2.5}$ and $\mathrm{Hf}_{69.5} \mathrm{Al}_{7.5} \mathrm{Ni}_{11} \mathrm{Cu}_{12}$ containing MIQNP were subject to three processes designed to mechanically separate the MIQNP from the amorphous alloy; the metallic glass ribbons were abraded using regular sandpapers and diamond papers in method one, scraped with diamond scratchers in method two, and sliced with a microtome in the third method [1,2]. The resulting pieces were then examined by Scanning Electron Microscope, Transmission Electron Microscope, and Energy Dispersive X-ray Spectroscopy.

It has been revealed that the mechanical breaking processes cause an undesired phase transformation of the quasicrystalline nanoparticles to the crystalline phases. The reason for this undesired phase transformation was analyzed and appropriate procedures to avoid this negative effect were made. To suppress localized temperature increase, several measures were taken in both method one and two. Sample preparation was conducted while the suitably annealed ribbons were submerged in water or alcohol. In some of the experiments, dry ice was added to the alcohol to lower the temperature further. However, electron diffraction pattern analysis showed the distribution of icosahedral quasicrystalline, glassy, and crystalline phases to be independent from the cooling methods used.

Results showed that the separation of the MIQNP from the metallic glass ribbon by mechanical processes was possible. Evidence of this is shown for the $\mathrm{Hf}_{69.5} \mathrm{Al}_{7.5} \mathrm{Ni}_{11} \mathrm{Cu}_{12}$ composition in Fig. 1. Note that in (a), the ratio of OB to OA was measured to be 1.62 and in (b), the spots marked with arrows show the structure's fivefold symmetry. Both are characteristic of the icosahedral quasicrystalline phase. On the TEM image of Fig. 1(c), circular areas marked with arrows correspond to MIQNP. For contrast, the diffraction pattern of the crystalline phase of $\mathrm{Zr}_{70} \mathrm{Cu}_{27.5} \mathrm{Rh}_{2.5}$ is shown in Fig. 2.

The success rate for the separation of MIQNP was far greater for the metallic glasses of composition $\mathrm{Hf}_{69.5} \mathrm{Al}_{7.5} \mathrm{Ni}_{11} \mathrm{Cu}_{12}$. Two factors are considered to contribute to this success. First, the crystallization temperature of $\mathrm{Hf}_{69.5} \mathrm{Al}_{7.5} \mathrm{Ni}_{10} \mathrm{Cu}_{11}$ metallic glass is typically $150{ }^{\circ} \mathrm{C}$ higher than that of $\mathrm{Zr}$-based metallic glasses, implying that Hf-based metallic glasses can endure a higher temperature increase compared to $\mathrm{Zr}$-based ones. Second, the annealed $\mathrm{Hf}_{69.5} \mathrm{Al}_{7.5} \mathrm{Ni}_{10} \mathrm{Cu}_{11}$ metallic glass is brittle, as evidenced by the fact that it breaks easily in $180^{\circ}$ bending. Therefore, the mechanical breaking of the $\mathrm{Hf}_{69.5} \mathrm{Al}_{7.5} \mathrm{Ni}_{10} \mathrm{Cu}_{11}$ induces a lower temperature increase as compared to alternative compositions, which would contribute to the high yield of unchanged MIQNP [3]. 


\section{References:}

[1] C. Li, Limin Wang and Akihisa Inoue, "Precipitation of Icosahedral Quasicrystalline and Crystalline Approsimant Phases in Zr-Cu-(Co, Rh or Ir) Metallic Glasses”, Journal of Non-Crystalline Solids 306 (2002)175-181.

[2] C. Li and Akihisa Inoue, "Precipitation of icosahedral quasicrystalline phase in $\mathrm{Hf}_{69.5} \mathrm{Al}_{7.5} \mathrm{Ni}_{11} \mathrm{Cu}_{12}$ metallic glass", Journal of Material Research, 16 (2001) 1190-1194.

[3] Financial support by National Science Foundation (DMR-1229063) is acknowledged.
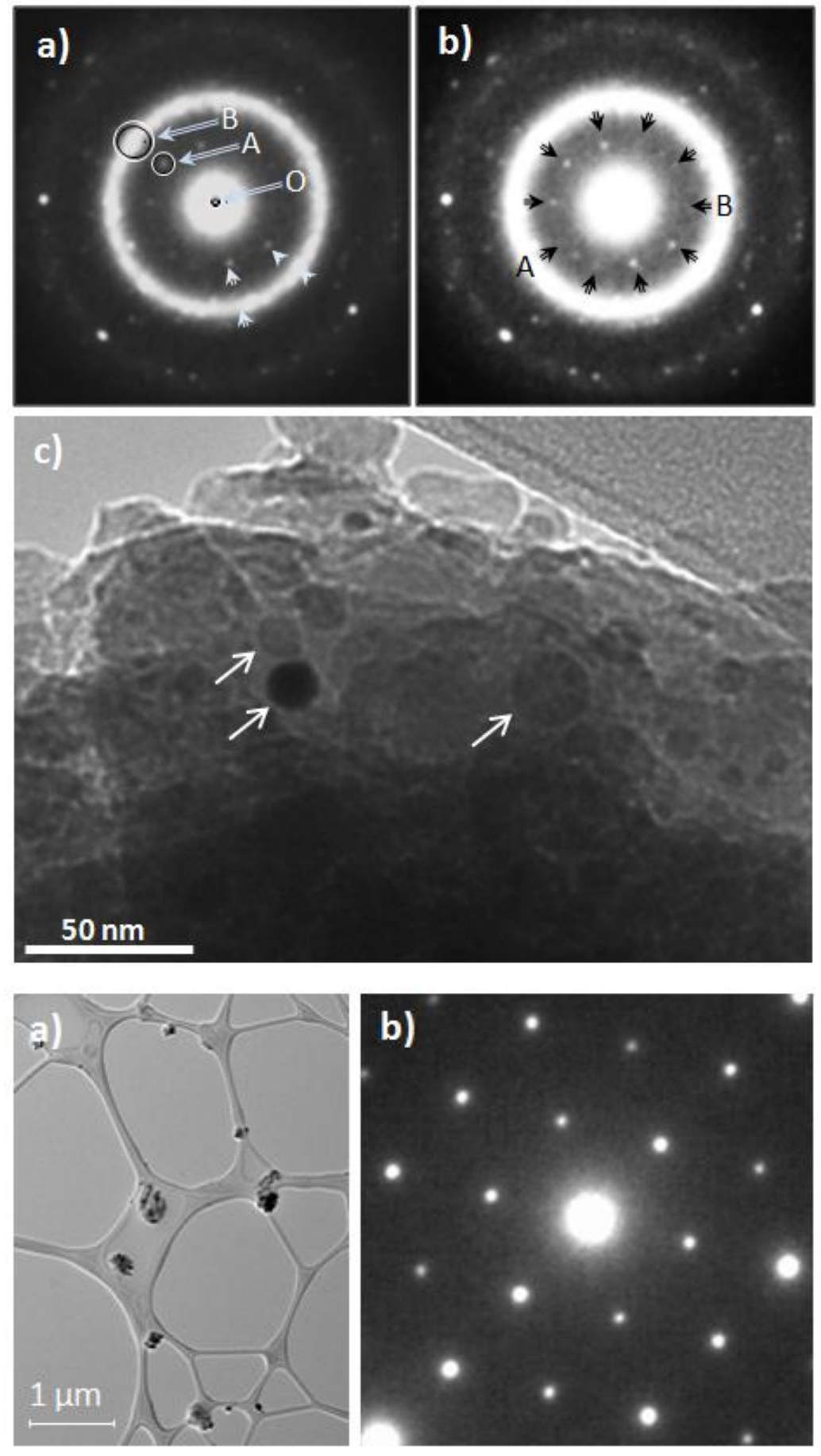

Fig. 1: Electron diffraction patterns (a)-(b) and TEM image (c) of small pieces obtained from annealed $\mathrm{Hf}_{69.5} \mathrm{Al}_{7.5} \mathrm{Ni}_{10} \mathrm{Cu}_{11}$ metallic glass by method two. (a) and (b) are from the same electron diffraction pattern with brightness and contrast adjusted to different levels to emphasize different features. Areas corresponding to MIQNP on the TEM image (c) are marked with arrows.

Fig. 2: TEM image (a) and electron diffraction pattern (b) of small pieces from the metallic glass of $\mathrm{Zr}_{70} \mathrm{Cu}_{27.5} \mathrm{Rh}_{2.5}$ composition obtained by method one. 